\title{
Toward a critical pedagogy of visual culture: Mapping the socioscopic
}

\author{
Kevin Tavin
}

We supply you with everything you need for successful living

(Diesel clothing advertisement, 1996)

\section{Introduction}

From 1996 to 1997, I taught elementary education students, enrolled in "Visual Arts in the Elementary School," using a progressive discipline-based art education model that revolved around one or more works of art. In the fall of 1997, I deviated from previous semesters by including essays, seminars, and projects dealing with the pedagogy of popular culture. Initially, my students were very resistant to this new information. They argued that many of the essays "over analyzed" popular culture and wondered what this had to do with educationmore specifically, art education. Most students refused to recognize popular culture as a meaningful project to be taken up in their future classrooms. My task was clear. I needed to use my students' memories of childhood to legitimate the power of popular culture.

I drew a line down the center of the chalkboard and on one side asked them to list all of the artists that they had learned about in their kindergarten through high school art education. In both sections of the class, the students recalled no more than twelve artists - all of them were dead, white, male, and European. They struggled to describe any of these artists' accomplishments (although half the class remembered that VanGogh "cut off his ear") and had difficulty relating the relevance of these 'men' and their art to their own lives. On the other half of the board I divided the space into four sections and labeled them children's' television programs, films for children, toys, and breakfast cereals. I asked the class to list as many images as they could recall from their childhood and to accompany each image with a brief explanation. The ensuing discourse exposed a celebration of shared private experiences with public forms. As the list expanded, students started singing advertisement jingles, television theme songs, and recalled specific episodes and products. They shared dynamic narratives of encounters with toys, recalled the specific imagery on a multitude of cereal boxes, and discussed specific actors on television shows. The dynamic intersection of collective and individual memories allowed the students to reveal their connections to one another in a vociferous manner. These memories amplified the echoes of investment that the themes, images, and sounds identified. Indeed, due to their excitement, I had a difficult time managing the class. When all had settled, I asked my students where the dominant site for learning is- inside or outside of school? We all agreed that a majority of learning takes place through popular/visual culture. 
To help demonstrate the pedagogical power of contemporary popular/visual culture we examined an advertisement for Diesel clothing from Rolling Stone magazine. The advertisement is an appropriated image of the Yalta Conference from 1945 in which women, wearing Diesel clothing (or lack thereof), are juxtaposed with Stalin, Roosevelt, and Churchill. I presented this advertisement to my class and posed questions for them to consider. These questions included: What is the main idea in this image- what does it portray? How are the words and images combined to present an idea? Have you seen this image or any part of this image before? If so, where? What does it remind you of? What other images does it call to mind? What questions does this image raise? What does this image say about the world and your experience of it? Does it represent any desires, beliefs, fantasies, or fears? How are certain groups or individuals represented in this image? I posed these questions and engaged my students in a dialogic process of interpretation.

As the students responded to my questions, and to each other, I tried to problematize some of their comments by raising questions regarding cultural power and the politics of representation. We discussed how history was erased or rewritten through this advertisement. We investigated how this image problematized social relations and historical fact. As the discussion continued, I raised questions concerning the symbolic representation of the women. Are the women in this advertisement trivialized in terms of their use as sexual objects? Are they stereotyped in any fashion? Does this advertisement, and others like it, help shape our understanding of the role of women in American society? What is the relationship between our view, or gaze, and the positions of the models. Does our gaze replicate unequal power relations between men and women? Some female students discussed their own experience of being objectified. Other women discussed their subjugated role in society and the mistreatment they have received from men. I asked the class whether this advertisement promoted a certain type of relationship between men and women at conferences? Was there a clear delineation between mind (male) and body (female)? Was the image relegating women to the role of play-things?'

As my students continued to present their ideas to the class, they seemed to recognize the growing number of connections between their knowledge, experiences, ideas and memories and the images in the advertisement. Their responses depended upon, and were triggered by, spirals of referentiality-intertextuality. Intertextuality refers to a continuous process of signification- lifting meanings and subjectivities from one text and situating them within another. Intertextuality "indicates multifarious and historically variable relations between texts. . . a mesh of textual systems" (Payne, 1996, p. 259). In this sense, 'texts' can be images, words, actions, or any set of interrelated methods and practices. These texts are not static, predetermined or pre-defined. They are produced within "historical and cultural contexts which shape them. . .(and) encompass silences, incoherences, (and) contradictions (Morgan, 1991, p. 153). Each text is interrelated with and interdependent on other texts that have proceeded or followed it. 
Throughout the remainder of the semester we investigated a plethora of visual images in contemporary culture. We looked at television, film, print advertisements, CD covers, toys, bulletin boards, comic books, and clothing. We asked the similar questions regarding each image and reflected upon important societal issues gleaned from intertextual interpretations. My students began to see how their identities, and the identities of their future students, are constructed through visual culture.

\section{Challenging the role of art education in (the) light of visual culture: A statement of the problem}

In the past, when ancient dudes cruised, they used the stars to lead their way. This was not a very excellent system because they were lost all day and ended up living in bogus caves. But luckily we dudes of today have a most excellent number of highways and many busy streets, and even more excellent than that-they've all been built right next to McDonalds. (McDonalds television advertisement, 1995)

Students live in and through mass media and popular culture. They fashion their sense of history, ideology, and multiple and ever changing identities through popular visual imagery. These images penetrate and pervade every aspect of students' lives in the form of television programs, children's books, advertisements, movies, comics, toys, cereal boxes, video games, fashion merchandise, sport shoes, fast food paraphernalia, and architectural and public spaces. These pervasive, immediate and sometimes ephemeral images construct students' consciousness and their sense of identity, politics, and culture. In other words, visual culture increasingly dominates our students' sense of reality and the way they define themselves and the world around them. Visual culture transmits knowledge, language, codes, and values that become the 'material milieu' of everyday social and discursive formations (Grossberg, 1992). The pleasure, enjoyment, and passion one receives through visual culture articulates particular ideological investments. Consumption, self-gratification, materialism, patriarchy, and racism can be authorized through relations of pedagogy and power in visual culture. These investments help students (and teachers) decide what matters, and what does not. In other words, these various investments act to form a consensus of particular social relations- the social imaginary (Aronowitz \& Giroux, 1991; Giroux \& Simon, 1989; Grossberg, 1992). This rapid proliferation of imagery has profoundly changed American culture and academia, yet art education hasn't quite caught up. Like the "ancient dudes" of past, many art educators use the "stars" of high culture- 'artworks'-to lead their pedagogical way.

The notion that there is something inherently special about fine artworks, when compared to other types of images, remains paramount within most current art educational theory and practice. Unlike the experience my students had, most art education praxis ignores the importance of popular images as a means for developing a more critical understanding of experience- both in and outside the school. Indeed, art education curricula rarely contains examples from popular culture or mass media (Wilson, 1997). In restricting student inquiry to legitimate 
'artworks' from the museum realm, art educators, consciously and unconsciously, exclude an expansive range of imagery and remain in the modernist paradigm of high culture-"living in bogus caves."

While art education praxis remains tethered to high culture, other fields of study have provided road maps to negotiate the "most excellent number of highways and many busy streets" in a postmodern society. Scholars in various areas have mounted impressive intellectual challenges to basic assumptions regarding the (il)legitimacy of high culture. Indeed, the spread of visual culture has shifted the ground of scholarship away from fossilized art disciplines designed to preserve high culture to more hybridized fields of study. For example, within the area of art history, some art historians are moving away from the history of art as a record of the creation of aesthetic masterpieces towards a broader understanding of their cultural significance and potential meaning within the context of contemporary society. In academia, the (anti)disciplines of cultural studies and critical pedagogy have problematized the role of popular images in order to investigate the dynamics of power, privilege, and social desire. Cultural studies attempts to understand how individuals and groups are affected by various forms of symbolic and material value, including popular visual culture, that either constrain or enable various forms of agency. By deconstructing and reconstructing the articulations between and among the various social structures and circuits of values in everyday life, cultural studies attempts to understand and transform culture. Critical pedagogy promotes interdisciplinary and transdisciplinary border crossings in order to help students negotiate the terrains of popular culture. Students are encouraged to critique popular culture texts in order to (re)construct meaning out of their lives and develop critical agency for promoting democratic public spheres, emancipatory agendas, ethical imperatives, and social justice.

In addition to cultural studies and critical pedagogy, a transdisciplinary field of study called "visual culture" attempts to interpret and understand the wealth of visual experiences in contemporary culture. This new and exciting field of study poses questions regarding how the construction and consumption of knowledge is articulated through notions of privilege, power, history, and pleasure-all within the intertextual circulation of images. Moreover, visual culture, as an transdisciplinary academic rubric, addresses social, economic, and political issues of representation while problematizing notions of vision, addressing issues of aesthetics, and embracing new genres of art history. In this sense, visual culture converges upon the inner and outer boundaries of art, architecture, film theory, media analysis, while intersecting with models of anthropology, philosophy, critical theory, and political discourses of identity formation. In other words, visual culture focuses on the cultural construction of visual experience in everyday life-the socioscopic.

These three areas of study - cultural studies, critical pedagogy, and visual culture - try to remap the once rigid boundaries of modernism while decentering disciplinary hegemony. These fields (re)theorize culture as an indeterminate set of discursive spaces mapped along circuits of representation, power, and politics. This notion (re)frames the division between high and low 
culture as a political position rather than a defensible intellectual or aesthetic distinction. The practices of visual culture, cultural studies, and critical pedagogy constitute a general attempt to transgress the borders sealed by modernism by proclaiming the arbitrariness of all boundaries and reframing the sphere of culture as a shifting social and historical construction. Furthermore, these fields of study generate theories such as intertextuality and nonlinearity that challenge traditional notions of authorship and status relations to 'texts,' while serving as pedagogical laboratories for reconstruing consciousness, subjectivities, and collective and interactive agency.

\section{Dissertation Overview}

What those of us who study visual representations need right now - if we are going to continue to produce new and unsettling questions rather than just tacitly reproduce canonized knowledge - is the disorderliness of spaces in conflict, the mayhem of the unknown, even if the resulting intellectual fracas sometimes feels like hell (Holly, 1996)

My dissertation examines the implications of these shifts in culture and academia toward the study of 'visual/popular culture' for their import to art education. Through research, observations, and interviews, I examine the interdisciplinary and transdisciplinary relationships between visual culture, cultural studies, and critical pedagogy. The nexus of these (anti)disciplines provide the theoretical, methodological, and ideological concepts that I use to challenge contemporary art education praxis. The purpose for my inquiry is to critique current art educational theories and practice and argue for the development of a critical intertextual framework for creating and interpreting visual culture and facilitating a broader system of social interaction.

What type of new theoretical, methodological, and ideological spaces would be opened for the field of art education if it embraced concepts from the areas of visual culture, cultural studies, and critical pedagogy in an transdisciplinary fashion? How do these areas inform one another? How do they contest one another? What are the risks involved in developing and implementing new forms of art education curricula based on the intersections of visual culture, cultural studies, and critical pedagogy? What happens to traditional notions of art-making and art interpretation in a transdisciplinary approach? My dissertation addresses these issues by situating art education, visual culture, cultural studies, and critical pedagogy within broader political, pedagogical, and cultural considerations.

My dissertation begins by examining visual culture, cultural studies, and critical pedagogy in relation to current art educational practices. I present a critical study of the theoretical frameworks of visual culture, cultural studies, critical pedagogy, and art education and the relationships between and among them. Each area is examined in depth as a hybridized site of theoretical convergence and contention.

The function and legitimacy of each area is examined and critiqued. The theoretical, methodological, and ideological concepts of visual culture, cultural 
studies, and critical pedagogy is problematized in relationship to current approaches to art making and interpretation. A review of the scholarly work of W.J.T. Mitchell, Martin Jay, Michael Ann Holly, Keith Moxey, and Irit Rogoff explicates historical, theoretical, and practical shifts in various fields of visual studies and art history toward the transdisciplinary project of visual culture. A review of the literature on cultural studies by such scholars as Joe Kincheloe, Lawrence Grossberg, Douglas Kellner, and Stuart Hall helps contextualize cultural studies within a wider social sphere, and provide connections to the academic rubric of visual culture. A review of the literature by critical pedagogues such as Henry Giroux, Roger Simon, Ira Shor, and David Trend provide important historical, theoretical, and ideological concepts regarding critical pedagogy that have significance to the areas of visual culture and cultural studies.

My dissertation then addresses the contributions of two art education students who created computer mediated montages; works of art that problematized traditional notions of art-making and art interpretation. The first student's montage critiques the political economy, labor struggles, and visual iconography of the Nike corporation, while the second student's montage critiques the stereotyping of African-American women in popular culture. Both students' art works are examined within the context of visual culture, cultural studies, critical pedagogy and art education. Specific areas of their projects are explicated, such as the textual analysis of everyday images/objects, the investigation of the circuits of culture, and the analysis of the intersections of art, power, and knowledge. These art works are also examined within the context of traditional notions of authorship and collective and interactive agency. An interview with both students follows which outlines and evaluates the theoretical framework of their projects.

The final phase of my dissertation is comprised of conclusions drawn from the relationships between and among visual culture, art education, cultural studies, critical pedagogy, and the varied experiences of my students. The benefits and liabilities of adopting new forms of visual cultural production and interpretation within the field of art education is discussed.

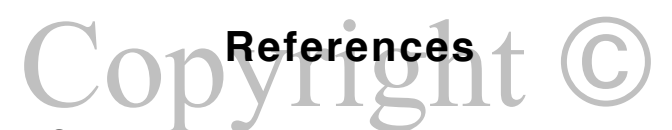

Aronowitz, S. \& H. Giroux. Postmodern education: Politics, culture, and social criticism. Minneapolis: University of Minnesota Press, 1991.

Giroux, H. \& Simon, R. Popular culture: Schooling and everyday life. New York: Bergin \& Garvey, 1989.

Grossberg, L. We gotta get out of this place. New York: Routledge, 1992.

Holly, M. Saints and sinners. October, 77(1): 39-41. 1996. 
Morgan, W. Deconstructing texts, reconstructing courses for textual literacy. In P. Cormack (e d.), Literacy: Making it explicit, making it possible. Adelaide: Australian Reading Association, 1991.

Wilson, B. Is art education obsolete? Partial draft of a keynote address presented at the 1997 International Symposium in Art Education. Taipei, Taiwan, R.O.C. , 1997a.
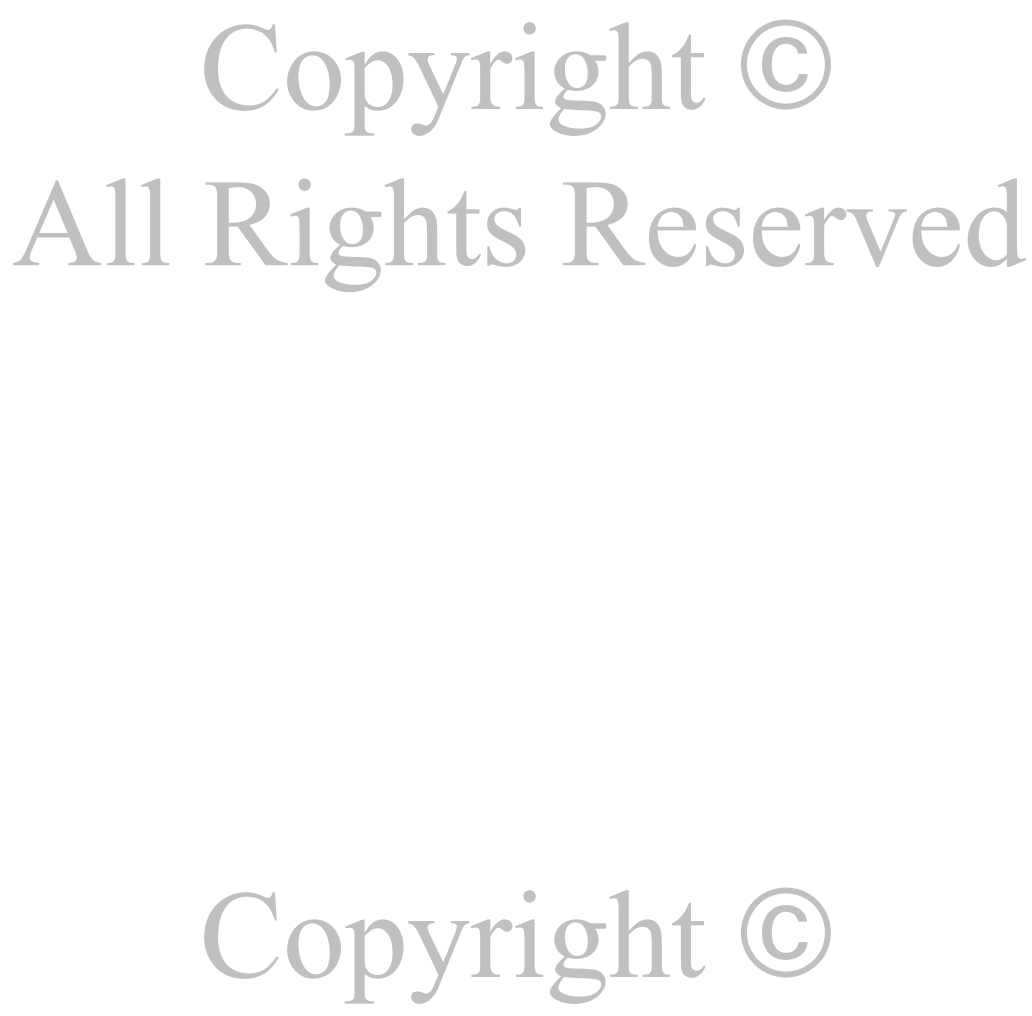

All Rights Reserved 